\title{
Diseño de un Sistema de Planificación de Recursos Empresariales (ERP) para una Microempresa
}

\section{Design of an Enterprise Resource Planning system (ERP) for a Microenterprise}

DOI: http://dx.doi.org/10.17981/ingecuc.13.1.2017.08

Reporte de caso. Fecha de recepción: 19 de octubre de 2016. Fecha de aceptación: 28 de diciembre de 2016

Rick Kevin Acosta Vega

Universidad Antonio Nariño. Santa Marta, Colombia

rick.acostav@gmail.com

Óscar José Ospino Ayala

Universidad del Magdalena. Santa Marta, Colombia

oscarospino2010@gmail.com

Víctor Enrique Valencia Espejo

Universidad del Atlántico. Barranquilla, Colombia

vvalenciaespejo@gmail.com

Para citar este artículo:

R. K. Acosta Vega, O. J. Ospino Ayala y V. E. Valencia Espejo, "Diseño de un sistema de planificación de recursos empresariales (ERP) para una microempresa," INGE CUC, vol. 13, no. 1, pp. 84-100, 2017. http://dx.doi.org/10.17981/ingecuc.13.1.2017.08

\section{Resumen}

Introducción- El sector textil y de confecciones a nivel mundial se ha en contrado en crecimiento durante los últimos años, sin embargo, se encuentra conformado, en su gran mayoría, por MiPyMES que presentan enfoques gerenciales obsoletos que conllevan en una administración ineficiente de los recursos empresariales de la organización; es por esto que surgen sistemas de información (CRM, MRP, MRPII, ERP...) como alternativas interesantes de solución para los problemas administrativos identificados comúnmente. Objetivo-El presente artículo tiene como finalidad el diseño de un sistema de planificación de recursos empresariales en una microempresa, con sus objetivos secundarios enmarcados en la realización de un estudio de viabilidad, preparación, modelización, parametrización, instalación y producción del sistema informático.

Metodología-Se utiliza una metodología que consta de una serie de fases en las que cada una posee variables de entradas (información), transformación de estas variables y variables de salida, que entregan como resultado el sistema ERP finalizado.

Resultados-Se logró el diseño completo del sistema informático, aunque, por motivos económicos por parte de la organización, se efectuó la implementación de los módulos de mayor relevancia para el mejoramiento com petitivo de la empresa, y se planteó que progresivamente ésta fuera adquiriendo los módulos faltantes.

Conclusiones- se destaca la viabilidad del diseño e implementación de sistemas de información complejos como el ERP con algunas consideraciones en las micro, pequeñas y medianas empresas, llevando a cabo un seguimiento periódico de los cambios positivos efectuados en la organización.

Palabras clave- Módulos del sistema, software, sistema ERP, competitividad, integración

\section{Abstract}

Introduction- The textile and clothing sector in the world has been in growth during the last years, however, it is conformed by MiPyMES which present old managerial approaches which lead to inefficient administration of the organization's business resources; for this appear information systems (CRM, MRP, MRPII, ERP...) as an alternative solution to administrative problems of the organization.

Objective- The present article aims an enterprise resource planning system design in a micro-enterprise, with their secondary objectives in the realization of a feasibility study, preparation, modeling, parameterization, installation and production of the computer system.

Methodology- Using a methodology that consists of a series of phases, in which each one has variables of inputs (information), transformation of these variables and variables of outlets, which both delivered the completed ERP system as a result.

Results- This was achieved the complete design of the system but for economic reasons by Parties of the Organization, was the implementation of modules of greatest relevance for the competitive improvement of the company, and was raised that this was progressively acquiring the missing modules.

Conclusions- It highlights the viability of design and implementation of complex information systems as the ERP with some considerations in micro, small and medium enterprises, Carrying out regular monitoring of positive changes in the organization.

Keywords- Modules of the system; software; ERP system; competitiveness; integration. 


\section{Introducción}

El sector textil/confecciones a nivel mundial se ha encontrado en crecimiento en los últimos años, esto gracias al aumento del consumo del ser humano y al esparcimiento del estilo de vida que brinda la urbanización [1], sin embargo, muchas son las empresas colombianas de este sector (en su mayoría mipymes) que se enfrentan a diversos factores como los enfoques gerenciales obsoletos, la integración de los gastos familiares en la contabilidad de la empresa y la falta de un perfil gerencial para hacer asociaciones, lo cual impide el desarrollo de la organización [2]. Lo anterior ha conllevado a un mal control de las diferentes áreas de la compañía, actuando con base en la experiencia y de forma intuitiva [3], olvidando que las utilizaciones de sistemas de información mejoran la calidad del sistema y favorecen el rendimiento organizacional de la empresa [4]. Una opción efectiva es el sistema de información integral ERP que se ajusta a las necesidades de la empresa; con ésta, la información que antes se fragmentaba en muchos sistemas distintos ahora se guarda en un solo almacén de datos exhaustivo que se puede utilizar por muchas partes distintas de la empresa [5]. De esta forma, hay un mayor control de artículos, documentos y datos relevantes en pro del mejoramiento continuo y la toma de decisiones gerenciales, dando beneficios económicos para la empresa.

Casa Glamel, que es una microempresa ubicada en la ciudad de Santa Marta (Magdalena) perteneciente al sector textil/confecciones, ofrece esencialmente el servicio de alquiler de prendas de vestir a las personas, así como la posibilidad de producir dichas prendas según los requerimientos del cliente para satisfacer sus necesidades en cuanto a vestuario se refiere. Esta microempresa ha presentado fallas en el control y gerenciamiento de su información para el manejo de sus documentos, así como en las unidades que se encuentran dentro y fuera de su almacén, además, posee poco acceso a datos de proveedores, como de sus finanzas y clientes. Para solucionar esta problemática resulta favorable el diseño de un sistema de planificación de recursos empresariales a través de una estructura que contemple un estudio de viabilidad, preparación, modelización, parametrización, instalación y producción de un sistema informático que se ajuste a sus necesidades y facilite la integración de las diversas áreas de la empresa, permitiendo un mayor control sobre sus activos inventariados, procesos logísticos, productivos, contables, de marketing y financieros.

Los problemas presentados por la organización han traído consigo consecuencias negativas no deseadas, que, a su vez, ocasionan un aumento de sus costos y que se reflejan en la disminución de utilidades por el mismo concepto; esto debido a que solo en manejo de inventario los costos se encuentran entre el $20 \%$ y el $40 \%$ del valor de la mercancía inventariada [6]. Es por ello que se necesita un buen control de los mismos, además, en la actualidad, las nuevas formas de negocios se centran en sistemas de informaciones integrales junto al Internet, e-commerce y negocios en línea [7].

$\mathrm{Al}$ realizar el diseño del sistema ERP en Casa Glamel, se pretende solucionar los problemas presentados y aumentar la competitividad de la empresa. Además, se busca disminuir la desconfianza y el temor que presentan las organizaciones para relacionarse con la academia [2] entregando a la comunidad investigativa una forma aplicativa de llevar a cabo el diseño de un sistema tan com plejo como éste.

\section{Revisión Literaria}

\section{A. Sistema de información ERP y sus principales características}

La referencia [5] presenta que un sistema de información es un conjunto de componentes interrelacionados que recolectan (o recuperan), procesan, almacenan y distribuyen información para apoyar los procesos de toma de decisiones y de control en una organización. Además de apoyar la toma de decisiones, la coordinación y el control, los sistemas de información también pueden ayudar a los gerentes y trabajadores del conocimiento a analizar problemas, visualizar temas complejos y crear nuevos productos; sin embargo, para que un sistema de información pueda brindar un buen soporte en la toma de decisiones de la compañía y entregue un mayor control, es necesario que estos realicen las actividades de entrada o captura de datos, procesamiento, salida y retroalimentación.

Cabe aclarar que un sistema de información no es un sistema informático, debido a que el sistema informático consiste en la compleja interconexión de numerosos componentes de hardware y software, los cuales son básicamente sistemas deterministas y formales, de tal forma que con un input determinado siempre se obtiene un mismo output. Los sistemas de información son sistemas sociales cuyo comportamiento se ve en gran medida influido por los objetivos, valores y creencias de individuos y grupos, así como por el desempeño de la tecnología. Así, el comportamiento del sistema de información no es determinista y no se ajusta a la representación de ningún modelo algorítmico formal [8].

Así pues, los sistemas de información surgen con la aparición y propagación de la computación desde la década de 1960, cuando ésta se comenzaba a orientar hacia los negocios. De esta manera, el 
concepto ha cambiado a lo largo del tiempo, pasando de ser un sistema de control de inventario básico, luego un MRP I y MRP II, hasta llegar finalmente a ser los ERP de hoy [9].

Por ello, un ERP, según [10], es un conjunto de programas que cumplen las características de ser un sistema integrado, parametrizable y práctico que permite compartir datos entre los miembros de la organización y facilitar la producción y el acceso a la información en tiempo real.

Debido a esto, en [11] se proporciona un estudio en donde se muestra que el sistema informático (software) del sistema de información ERP está compuesto de diferentes módulos básicos y extendidos que dependen, en gran medida, del alcance de la organización.

\section{B. Proyecto para la implementación del ERP}

El mero diseño no es suficiente, se necesita lograr una implementación exitosa de un sistema de planeación de recursos empresariales (ERP); se debe realizar un proyecto de planeamiento donde se imprima las características de la empresa y los objetivos que se desean alcanzar. La referencia [12] sugiere una metodología para realizar una implementación de un sistema exitoso; ésta consiste en de 6 fases progresivas: estudio de viabilidad, preparación, modelización, parametrización, instalación y producción del sistema informático.

\section{III.Metodología}

Esta investigación cuenta con un enfoque cuantitativo, ya que se alcanzarán unos impactos y resultados que se evidenciarán en datos, cantidades y cifras estadísticas. Además, su alcance es de tipo correlacional debido a que se pretende conocer el grado de asociación que existe entre las áreas y procesos que se implementan en Casa Glamel para lograr interrelacionarlos a través de un sistema ERP que mejore su competitividad. Se toman la tecnología y los módulos del sistema como variables independientes, y el sistema diseñado como la variable de salida (dependiente).

Por ello, el estudio determina un impacto evidente a una población finita compuesta por cinco (5) personas, dos (2) administradoras y tres (3) colaboradoras, además de sus clientes. $\mathrm{Al}$ ser pequeño el universo de estudio, se facilita el proceso investigativo y no es necesario tomar una muestra. Así mismo, se hace uso de todos los procesos de los que dispone la empresa actualmente y puede adquirir en el futuro. Además, para el procesamiento de la información se hará uso de la calificación, tabulación y categorización analítica de datos.

Para el diseño del sistema ERP (Enterprise Resource Planning), se utilizó la metodología propuesta en [12], la cual se presenta en la Fig.1.

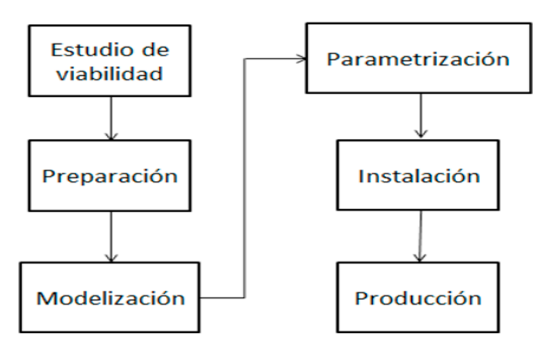

Fig.1. Metodología para el diseño del sistema ERP. Fuente: Modificado de [12].

Contando así con las siguientes fases:

\section{A. Estudio de viabilidad}

Se realiza para conocer la posibilidad de llevar a cabo la implementación del ERP. Este estudio contiene las siguientes actividades:

1. Propuesta de evaluación del proyecto presentado por la empresa proveedora.

2. Evaluación teniendo en cuenta las necesidades de la empresa.

3. Informe de la evaluación, que es el resultado de la evaluación realizada.

4. Estimación, que consiste en calcular en una proximidad el esfuerzo y el costo total que requiere el proyecto.

5. Propuesta de proyecto, la cual contiene los siguientes puntos: introducción y justificación del proyecto; visión de la dirección; entorno del proyecto; objetivos de la implantación; propuesta de implantación; organización del proyecto; entregas; recursos; políticas de calidad; soporte del proyecto; factores críticos de éxito; documentos de referencia; perfil de la empresa; metodología de implantación.

6. Preparación del contrato; éste se efectúa entre la empresa fabricante o consultora que se va a responsabilizar del ERP y la empresa destinataria del ERP.

\section{B. Preparación}

Se define un plan del proyecto y se prepara la empresa para acometerlo. Éste considera los siguientes puntos: informe del alcance y objetivos del proyecto; planificación e instalación de la infraestructura del proyecto; diseño del panorama del sistema ERP; manual del proyecto; y plan de comunicación del proyecto.

\section{Modelización}

Se realiza el diseño conceptual y se define un modelo de empresa, el cual considera como puntos importantes los siguientes: informe consolidado de modelización (modelo de negocio con el ERP, modelo organizativo con el ERP, modelo del sistema ERP); 
estrategia de conversión; esquemas de codificación de los datos maestros; e infraestructura técnica de producción.

\section{Parametrización}

Se realiza un diseño detallado y se construye un prototipo del nuevo sistema. Éste considera como puntos relevantes los siguientes: empresa modelo; sistema ERP completamente configurado; documentos de informes y formularios de salida; diseños y programas de interfaces; diseños y programas de conversiones, entre otras.

\section{E. Instalación}

Se prepara el sistema para la entrada en el régimen productivo, para ello, se prueban integradamente las nuevas funcionalidades. Como puntos relevantes se tienen: programas de formación de usuarios finales; pruebas de aceptación; puesta en marcha del soporte a la producción; calendario y guion para la conversión de datos, ente otros.

\section{F. Producción}

Se pone en funcionamiento real el nuevo sistema y se le da soporte. Éste considera como puntos relevantes los sistemas productivos en estado operativos; los primeros procesos en lotes; el primer soporte operativo; la revisión del proyecto de implantación; y los planes a medio plazo.

\section{III.Resultados}

\section{A. Estudio de viabilidad:}

Corresponde aquí evaluar la posibilidad de implantar el sistema ERP en la organización, estimando los esfuerzos que deben realizarse para ello. Este estudio consta de dos partes: la primera es la propues$t a$, en donde se dan respuesta a los requerimientos funcionales y no funcionales obtenidos previamente (como en el caso de esta investigación); y la segunda, la evaluación, en donde se aprecia el nivel de cumplimiento de dicha propuesta [13].

\section{1) Propuesta}

\section{- Estructura del software con base en los requerimientos funcionales.}

Aquí se establece que el sistema ERP contiene 4 grandes módulos: CRM, logística interna, gestión de talento humano y contabilidad y finanzas. Además de ello, que la forma en que éste entregue información al usuario dependa de la sección que se inicie, por lo cual se fijaron 3 secciones: recepción, coordinación y administración. Éstas se ajustan a las necesidades de la empresa, sus procesos y áreas; cada sección ofrece información diferente al usuario.

Sección de recepción. Con ésta, los trabajadores del área de recepción podrán ingresar al sistema. En la Fig. 2, se presentan los módulos, sub-módulos, categorías e información a la que tendrán acceso, los cuales se especifican más detalladamente en la fase de modelización.

Sección de coordinación. En la Fig. 3, se presentan los módulos, sub-módulos y categorías a los que puede ingresar el personal encargado del área de coordinación y la información que pueden obtener. En la fase de modelización se detallan estos en forma de proceso.

Sección de administración. En la Fig. 4, se presenta de forma estructural las entradas a las que puede ingresar el personal encargado del área administrativa, y, posteriormente, se describe la información que pueden conseguir. Éstas se especifican en la fase de modelización.

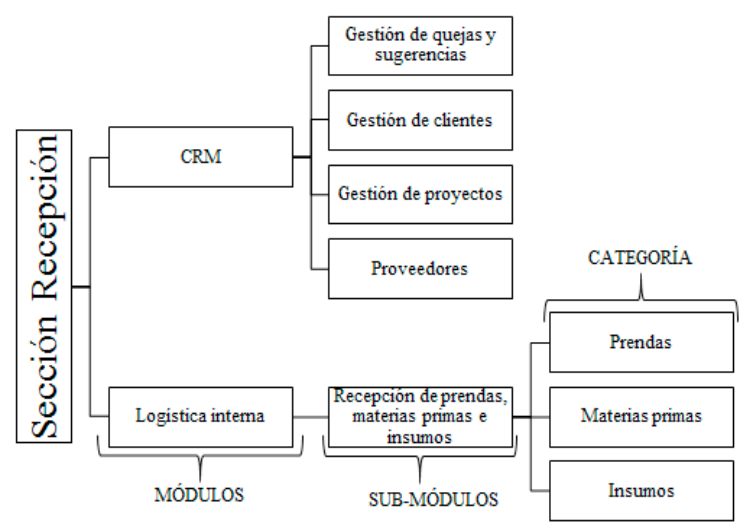

Fig. 2. Estructura de la sección de recepción. Fuente: Modificación de autores de [14].

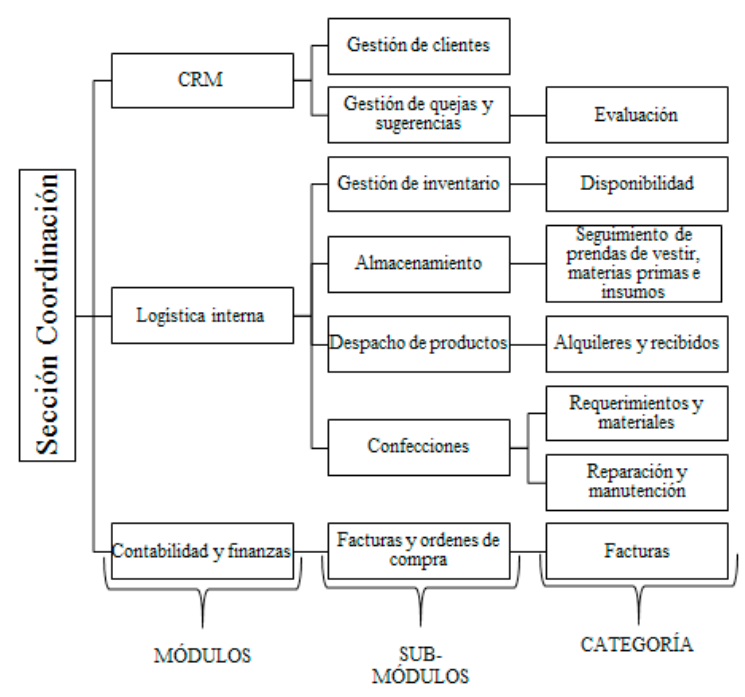

Fig. 3. Estructura de la sección de coordinación. Fuente: Modificación de autores de [14]. 


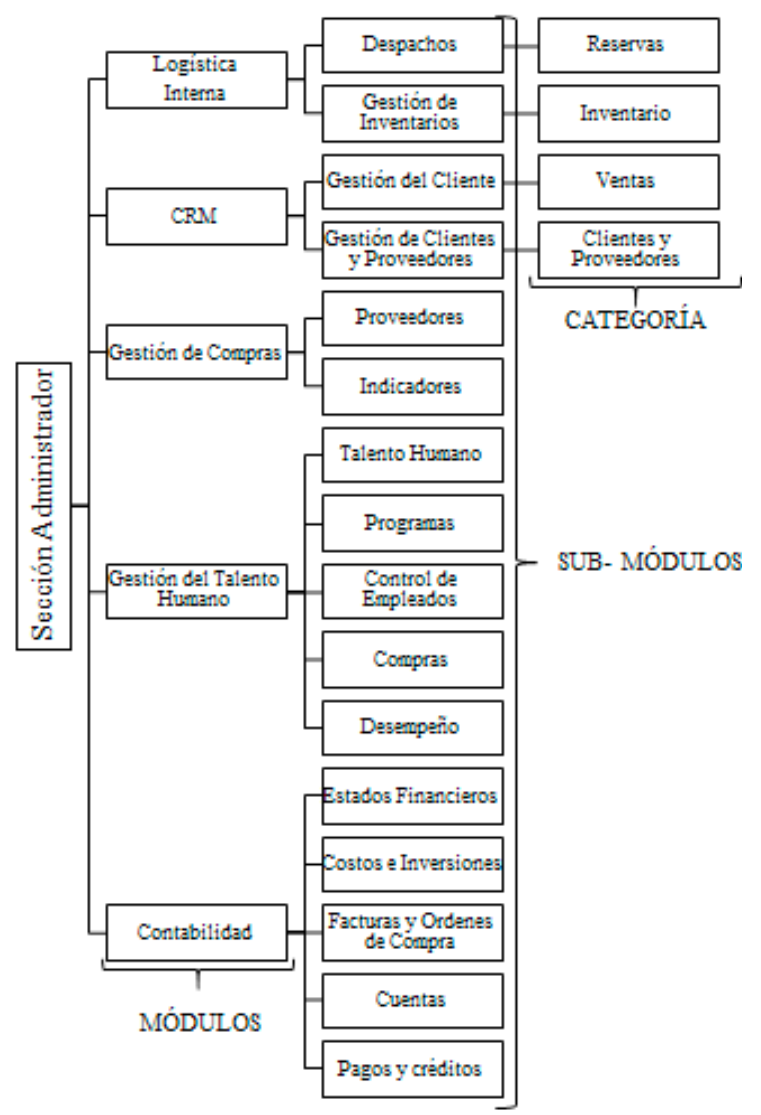

Fig. 4. Estructura de la sección de administración. Fuente: Modificación de autores de [14].

- Plataforma y herramientas de desarrollo.

Se podrá ingresar al sistema vía web. La plataforma se desarrollará con las siguientes tecnologías: HTML5 y CSS3; Python - Django; MySQL 5; Bootstrap; y Jquery.

En cuanto a la plataforma que soportará la aplicación, se tiene que: (1) el servidor web se realizará con Python y MySQL instalados; y (2) dada la naturaleza de la aplicación, no se requiere ningún sistema operativo en concreto, si bien se propone LINUX en su distribución debido a sus características y su coste 0 .

En lo que se refiere a clientes o navegadores de la aplicación para acceder, se tiene a: Google Chrome, Mozilla Firefox, Opera y Microsoft explorer 9.0 o superior. Además, cada responsable de su área tendrá uso de los módulos referentes a sus procesos, mas el área administrativa, podrá tener control de los precios y demás datos de relevancia e importancia para la organización. Así, los datos económicos y contables de la empresa solo podrán ser modificados por la sección de administración.

Concepto de desarrollo. Diseño gráfico: se utiliza la plantilla de diseño predefinida, la cual recurre a un diseño cuyo modelo está basado en una plantilla de catálogo disponible. Ésta no es costosa y permite una adaptación del diseño gráfico para la aplicación web.

Garantía y soporte. El periodo de garantía de la aplicación debe ser de mínimo 1 año tras la entrega del producto, siendo responsable la empresa programadora d cualquier problema de funcionamiento de la aplicación, sin coste alguno para Casa Glamel. Sin embargo, fuera del periodo de garantía, las mejoras propuestas por la organización después de la entrega y los costes por los problemas surgidos por el mal uso de la aplicación y los derivados del cambio de plataforma para la que ha sido diseñada la misma, serán asumidos por Casa Glamel. Así mismo, se ofrecen varios tipos de soportes para uso y gestión de la aplicación: telefónicos, correo electrónico y presenciales.

Licencia perpetua. La licencia solo se paga una vez y la aplicación se encuentra disponible por un periodo de tiempo ilimitado.

Evaluación. Se realiza la evaluación de la propuesta con ayuda de los encargados de cada área de la empresa (Tabla 1); de lo cual, se obtiene que el diseño propuesto atienda a las necesidades de cada área de la organización y la integra como un todo.

\section{B. Preparación.}

Ésta tiene como iniciativa asegurar el correcto arranque del proyecto y prever problemas, aquí se definieron: los participantes de proyecto, que serían los responsables de cada área, programadores e investigadores; los roles del usuario para evitar inconvenientes; la codificación de los artículos y prendas, la cual no existía en la empresa y se llevó a cabo por la familia, categoría y número (estos son datos maestros); los programadores, en donde se seleccionó al personal calificado realizándose el debido contrato; y los talentos humanos, empleándose el personal con experiencia en Casa Glamel para el desarrollo del proyecto [15].

\section{Modelización.}

Aquí se lleva a cabo la codificación y documentación de manera conceptual, así como la forma en que se realizarán los procesos en calidad del software [16].

\section{1) Módulos.}

En la Fig. 5, se presenta la estructura completa modelizada del sistema informático ERP, en donde se pueden observar cuatro grandes módulos y los diferentes sub-módulos saliendo de ellos. Esta forma es optimizada de la propuesta anteriormente establecida. 
TABla 1. Lineamientos Para EVALUAR EL SOFTWARE.

\begin{tabular}{|c|c|c|c|}
\hline \multirow{2}{*}{$\begin{array}{l}\text { Requerimientos } \\
\text { del software }\end{array}$} & \multirow{2}{*}{$\begin{array}{l}\text { Características } \\
\text { específicas del software }\end{array}$} & \multicolumn{2}{|c|}{ Evaluación } \\
\hline & & Sí & NO \\
\hline \multirow{3}{*}{$\begin{array}{l}\text { Efectividad de } \\
\text { desempeño }\end{array}$} & $\begin{array}{l}\text { Capaz de realizar todas } \\
\text { las tareas requeridas }\end{array}$ & $\mathrm{x}$ & \\
\hline & $\begin{array}{l}\text { Capaz de realizar todas } \\
\text { las tareas deseadas }\end{array}$ & $\mathrm{x}$ & \\
\hline & Capacidad adecuada & $\mathrm{x}$ & \\
\hline \multirow{5}{*}{$\begin{array}{l}\text { Eficiencia del } \\
\text { desempeño }\end{array}$} & $\begin{array}{c}\text { Tiempo de respuesta } \\
\text { rápida }\end{array}$ & $\mathrm{x}$ & \\
\hline & Entrada eficiente & $\mathrm{X}$ & \\
\hline & Salida eficiente & $\mathrm{X}$ & \\
\hline & $\begin{array}{l}\text { Almacenamiento de } \\
\text { datos eficientes }\end{array}$ & $\mathrm{X}$ & \\
\hline & Resalto eficiente & $\mathrm{X}$ & \\
\hline \multirow{6}{*}{ Facilidad de uso } & $\begin{array}{l}\text { Interfaz de usuario } \\
\text { satisfactorio }\end{array}$ & $\mathrm{x}$ & \\
\hline & $\begin{array}{l}\text { Menús de ayuda } \\
\text { disponibles }\end{array}$ & $\mathrm{X}$ & \\
\hline & $\begin{array}{l}\text { Archivos Léame para } \\
\text { notificar cambios de } \\
\text { últimos momentos }\end{array}$ & $\mathrm{X}$ & \\
\hline & Interfaz flexible & $\mathrm{X}$ & \\
\hline & $\begin{array}{l}\text { Retroalimentación } \\
\text { adecuada }\end{array}$ & $\mathrm{X}$ & \\
\hline & $\begin{array}{l}\text { Buena recuperación de } \\
\text { errores }\end{array}$ & $\mathrm{X}$ & \\
\hline \multirow{3}{*}{ Flexibilidad } & Opciones de entradas & $\mathrm{X}$ & \\
\hline & Opciones de salidas & $\mathrm{X}$ & \\
\hline & $\begin{array}{l}\text { Utilizable con otros } \\
\text { softwares }\end{array}$ & $\mathrm{X}$ & \\
\hline \multirow{3}{*}{$\begin{array}{c}\text { Canal de } \\
\text { documentación }\end{array}$} & Buena organización & $\mathrm{X}$ & \\
\hline & $\begin{array}{l}\text { Manual en línea } \\
\text { adecuado }\end{array}$ & & $\mathrm{X}$ \\
\hline & $\begin{array}{l}\text { Sitio web con preguntas } \\
\text { frecuentes }\end{array}$ & $\mathrm{X}$ & \\
\hline \multirow{3}{*}{$\begin{array}{l}\text { Soporte del } \\
\text { fabricante }\end{array}$} & $\begin{array}{c}\text { Soporte técnico } \\
\text { permanente en línea }\end{array}$ & & $\mathrm{X}$ \\
\hline & $\begin{array}{l}\text { Boletín correo } \\
\text { electrónico }\end{array}$ & $\mathrm{X}$ & \\
\hline & $\begin{array}{c}\text { Sitio Web con } \\
\text { actualización de } \\
\text { productos que se puedan } \\
\text { observar y ver sus } \\
\text { descripciones }\end{array}$ & $\mathrm{X}$ & \\
\hline
\end{tabular}

* El manual y soporte técnico en línea no es necesario, ya que este software es de uso exclusivo de la empresa, y en caso de que se necesite se puede contactar al programador del mismo. Además, se contará con un periodo de capacitación por lo que no se necesita de un manual propiamente dicho.

Fuente: [17]

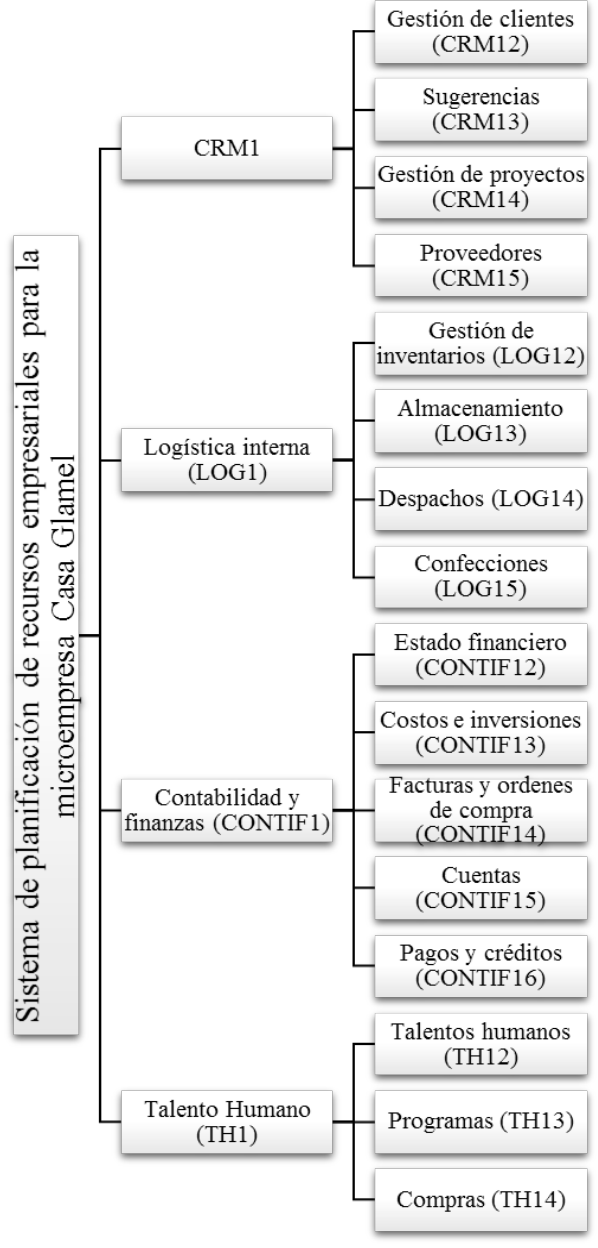

Fig.5. Estructura del ERP

Fuente: Modificación de autores de [14]

El proceso para acceder a los módulos, sub-módulos, categorías y niveles del ERP se explica a continuación:

Si la persona no cuenta con un usuario, éste debe ser creado y activado, con él se autentican sus datos, contraseña y los módulos e información a los cuales tendrá acceso (sección). Luego de ello, puede ingresar al sistema, al módulo requerido y permitido por su sección con las categorías y niveles contenidos.

\section{- Módulo $C R M_{1}$}

Tiene como propósito facilitar herramientas que permitan el manejo de la información de los clientes para la creación de relaciones fidedignas, y así mismo, llevar a cabo el gerenciamiento de campañas, sugerencias e información de proveedores. Aquí también se especifican los datos a ser tomados por parte del sistema, puesto que el corazón de un ERP es una base de datos central que obtenga datos de las aplicaciones, las cuales, a su vez, alimentan la base de datos [10]. 
Gestión de clientes $\left(C R M_{12}\right)$. Presenta una pantalla inicial que contiene el total de clientes existentes y potenciales de la empresa, así como el total de ventas realizadas, y con ello las siguientes categorías:

- Registro y consulta de clientes $\left(C R M_{121}\right)$. Almacena y actualiza la información de los clientes. $\mathrm{Al}$ ingresar a esta categoría aparece la opción de "crear clientes", que, al darle clic, entrega una ventanilla en donde se despliega una lista de los clientes junto con su información; además, aparecen las compras (confecciones) y alquileres hechos. Cabe resaltar que se puede realizar la consulta si se escribe el nombre y/o la identificación del cliente en un cuadro que se ubica encima de la lista de despliegue.

- Notas $\left(\mathrm{CRM}_{122}\right)$. Al ingresar al módulo CRM con la sección de administrador, aparecerá en su inicio un contador que indica las prendas que más se han alquilado, así como las ventas realizadas en términos de pesos y la demanda insatisfecha que no se ha podido atender.

- Estadisticas y seguimientos $\left(\mathrm{CRM}_{123}\right)$. Al darle clic aparecen las opciones de: (1) "reportes estadísticos", que contiene gráficas, promedios, desviaciones y frecuencias con respecto a las ventas, las evaluaciones hechas por los clientes de forma ponderada (deficiente, malo, regular, bueno, excelente) y las visitas realizadas por los clientes a los canales interactivos de la empresa; y (2) "devoluciones pendientes", donde, al dar clic, se muestra un listado de clientes pendientes por entregar y de aquellos que han pasado la fecha de entrega.

- E-mail $\left(\mathrm{CRM}_{124}\right)$. Este subnivel aparece dando clic a la categoría, en donde se pueden obtener y enviar correos masivos de interés a los clientes.

- Ventas $\left(\mathrm{CRM}_{125}\right)$. Se pueden conocer las ventas realizadas (confecciones y alquileres) durante un periodo de tiempo.

Para ello, al ingresar a este nivel, inmediatamente aparecen dos casillas, una pide la "fecha de inicio de búsqueda" y la otra la "fecha final de búsqueda”, y se da clic en consultar; luego, aparece la información solicitada.

Sugerencias y quejas $\left(C R M_{13}\right)$. Al dar clic, aparecen las opciones de: (1) "Registrar", se hace clic en ella, y luego en el marcador se selecciona si es una sugerencia o queja; después se digita, se selecciona la fecha, y luego se guarda. (2) "Consultar", si se selecciona esta opción, se despliegan las entradas de sugerencias o quejas; se hace clic en una de ellas y luego aparece un listado por fecha de las mismas. Éstas se pueden depurar para conocer las que han sido atendidas y cuales están pendientes, también se puede dar la opción de sugerencias o quejas atendidas o, por el contrario, pendiente al dar clic en ellas. Además de ello, se permite conocer el nivel de cumplimiento de las sugerencias y quejas atendidas por periodo.
Gestión de proyecto $\left(C R M_{14}\right)$. Permite administrar las campañas y proyectos en el marco de la fidelización de los clientes. Al desplegar esta categoría aparecen los siguientes niveles:

- Registros y consulta $\left(\mathrm{CRM}_{141}\right)$. Ingresando aparecen las opciones de: (1) "Registros", que al darle clic entrega un cuadro de diálogo en donde se pide el nombre del proyecto; a quién impactará; sus costos; el tiempo de planificación; la programación; los participantes; los entregables; y el cronograma de actividades. Por último, se da clic en guardar. (2) "Consultar", al dar clic aparece el listado de los proyectos con la descripción de: ejecutado, en planeación o en ejecución. Dando clic a cada uno de los proyectos, aparecen los costos, tiempos, beneficiarios, personal, resultados (esperados y/u obtenidos) y documentos consolidados (descripción), y, así mismo, se pueden modificar.

- Publicidad $\left(\mathrm{CRM}_{142}\right)$. Al ingresar con un clic aparecen los proyectos de publicidad realizados y los planificados. Si se entra a cada una de ellos, se encuentra un listado de la diferente publicidad, en donde si se da clic a cada una, se muestran los costos, los tiempos y los resultados obtenidos, y, en el caso de los planificados, los resultados que se esperan recibir.

- Encuestas $\left(\mathrm{CRM}_{143}\right)$. Al ingresar, aparecen las opciones de: (1) "Registro", en donde se pide la información sobre a quién va dirigida la encuesta, a quién impactará, los costos, el tiempo de planificación y programación, los participantes, los entregables y el cronograma de actividades; y (2) "Consultar", la cual suministra la información de las encuestas y da un reporte estadístico de los resultados.

Proveedores $\left(C R M_{15}\right)$. Al ingresar aparecen las opciones de: (1) "Registro", donde se ofrece un despliegue pidiendo como información el nombre, el logo, el RUT, el NIT, la dirección, los teléfonos, los productos que ofrece, el correo y la persona de contacto del proveedor. Luego de llenar todas las casillas, se habilita la opción de guardar; y en (2) "Consultar", aparece un listado de los proveedores con su debida descripción en donde se puede obtener información de los mismos. Existe también una casilla que permite digitar el nombre, NIT y/o RUT de los proveedores para consultarlos. Además de ello, hay una entrada para realizar modificaciones a la información básica de los mismos; por último, en la información también aparecen los cumplimientos y la calificación de los proveedores. Cabe resaltar que la calificación es entregada por el módulo de logística interna.

\section{- Módulo de logística interna (LOG $)$.}

Tiene como propósito: planificar, controlar y verificar el flujo y almacenamiento de materias primas, productos semi-elaborados o terminados, y el flujo de la información referente a este proceso desde el lugar de origen hasta el lugar de entrega al cliente. 
Gestión de inventario $\left(L O G_{12}\right)$. Al ingresar a esta categoría, aparece un cuadro que contiene ordenadamente lo siguiente:

- Inventario $\left(L O G_{121}\right)$. Si se ingresa a esta opción, se muestra una ventana que contiene como encabezado los siguientes sub-niveles:

Inventario existente $\left(L O G_{1211}\right)$. $\mathrm{Al}$ ingresar a éste se encuentra un cuadro que se puede ocultar y desplegar dando clic, el cual presenta las prendas por categorías, referencias, tipo, estado, tallas y precio. También está la opción de Search, en donde se pueden buscar prendas por sus referencias, tipos y estados, además de ello, si la lista de inventario se alarga, se podrá dar avance (next) y retroceso (last), ir al inicio (first), y también a los previos (previuos).

Productos disponibles $\left(L O G_{1212}\right)$. Al dar clic en éste, se presenta un cuadro que incluye las categorías, referencias, tipo, estado, talla y precio de cada una de las prendas que se encuentran disponibles. Así mismo, también se puede: agregar la disponibilidad de una prenda haciendo clic en el botón "+" ubicado en el encabezado del cuadro, en donde se debe diligenciar la información de las prendas (referencia, tipo, estado, talla y precio); consultarla; y modificarla, en cuanto a disponibilidad se refiere. Además, se puede reservar una prenda, la cual dejaría de ser disponible y pasaría a la categoría de reserva.

Productos en reserva $\left(L O G_{1213}\right)$. Al ingresar a este nivel se pueden conocer las prendas reservadas, para ello, se hace clic en éste y se encuentra una lista que contiene todas las prendas reservadas y la fecha a la cual se debe entregar al cliente. Al dar clic en cada una de las prendas de las listas, aparece la opción de "modificar", la cual permite hacer cambio en la fecha de retiro del cliente; también se cuenta con la opción "eliminar", en dado caso que la reserva sea cancelada; y por último, está la tentativa de descripción "alquilada", que hace que el producto pase de ser reservado a la categoría de alquilado.

Productos alquilados $\left(L O G_{1214}\right)$. Al dar clic e ingresar a él, aparece una lista en donde se pueden ver los productos alquilados, así mismo, es posible hacer consultas de ellos dando clic en la opción consultar, en donde se ingresa la referencia, se da clic en "consultar" y como resultado se obtiene un informe que presenta la fecha y el precio por el que fue alquilado, el cliente a quien fue entregado, la fecha de devolución pactada y el estado en el que fue recibido (buen estado o mal estado). Además, se puede depurar la lista de prendas por familia, categoría y fechas.

Productos con fallas $\left(L O G_{1215}\right)$. Al ingresar a éste, aparece un cuadro que presenta los productos dañados ordenados por fecha, así mismo, se pueden agregar a este nivel los productos dañados dando clic en la opción “+”, en donde se pide la información del motivo del daño en el producto (por uso, por accidente o mal uso del cliente). Después de diligenciada las casillas se hace clic en "guardar" y automáticamente se anexa a la lista. Así mismo, está la opción "consultar" en donde se ingresa la referencia, luego se da clic en "consultar" y se puede conocer el historial de una prenda con referencia a los daños presentados, la fecha y, en caso que sea por mal uso, muestra el cliente que ocasiono el daño a la prenda. Además, en el encabezado de la lista aparece la opción depurar, en donde se puede fragmentar la lista por fechas. Por último, en cada fila donde se encuentra la prenda, está la información referente a si el daño fue atendido o no; por defecto, el programa indica pendiente, pero si fue atendido, se pude modificar dando clic en él.

Seguimiento de prendas $\left(\log _{1216}\right)$. Aquí aparece un buscador en donde, al digitar la referencia del artículo, se genera un reporte de la misma con su estado, así como su respectivo historial de entradas y salidas.

Almacenamiento $\left(\mathrm{LOG}_{13}\right)$ :

- Seguimiento de prendas de vestir, materias primas e insumos $\left(L O G_{131}\right)$. Si se ingresa a éste, se puede encontrar un "buscador" que primeramente pide la categoría (prendas, insumos o materias primas), y seguidamente, pide la referencia; luego, al dar clic, se conoce la ubicación (si está en el área de almacenamiento o si por el contrario está en la bodega 1, 2 o 3, y en qué estante) y presenta el número de veces que ha rotado (esta información en el caso de las prendas es importante puesto que ayuda a que homogéneamente éstas sean alquiladas).

- Artículos $\left(L O G_{132}\right)$. Al ingresar, aparecen las entradas de "Prendas", "Materias primas" e "Insumos". Si damos clic en "Prendas" aparecen dos opciones: (1) "crear", en donde se pide la información del artículo y luego se guarda; (2) si se da clic en "ingresar", pide la referencia de la prenda que está siendo devuelta y el estado de la misma, y con ello se agrega al inventario. Cabe resaltar que este mismo proceso, se realiza también para materias primas e insumos, solo que se debe ingresar en esas opciones.

Despachos $\left(\mathrm{LOG}_{14}\right)$ :

- Alquileres y recibidos $\left(L O G_{141}\right)$. Esta categoría presenta los despachos efectuados por un periodo de tiempo deseado, las facturas salientes, los clientes a los que se les alquiló (éste genera un descuento en el inventario disponible y lo clasifica como alquilado), los abonos entregados por los clientes y, además, los recibidos junto con sus fechas. Si el cliente presenta demora con el regreso del alquiler, el software lo revelará y se le multa por ello (la información de los clientes morosos por devolución se comparte 
con el módulo de CRM). Además, permite agregar el estado en que llegó la prenda luego de un alquiler, y, en dado caso que haya un daño ocasionado por el cliente, se puede agregar el valor a la factura para que el cliente pague por ello. Así mismo, permite colocar en reserva un producto para el cliente, y entrega la notificación de la fecha de recogida suministrada en la reserva (que son 2 días antes que el cliente recoja el producto).

- Recibidos de nueva materia prima, insumos y prendas $\left(L O G_{142}\right)$. Al dar clic, se tienen las opciones de: (1) "materias primas o insumos", si se ingresa a ésta, aparece un listado de las materias primas ingresadas por orden de fechas; dando clic en ellas arroja un informe del proveedor, cantidad ingresada, así como el estado. Existe en el encabezado de la lista el símbolo “+”, si se da clic allí, se pueden agregar más unidades entrantes con la información necesaria (nombre, proveedor, cantidad, estado y fecha). Y (2) "prendas", parecida a la anterior opción, con la diferencia que para ésta, cuando se quiere registrar, se debe ingresar la referencia del producto y el lugar a donde va destinado (bodega 1, 2, 3 o almacén). Esta información de entradas es compartida con los sub-módulos de gestión de inventario y almacenamiento.

Confecciones $\left(L O G_{15}\right)$. Al dar clic en esta categoría aparecen las opciones de: (1) "materiales, insumos y materias primas", en donde se presenta una lista de ellos, así como las entradas, salidas y los usos recibidos; y (2) "reparaciones y mantenimiento", al dar clic se despliegan las sub-opciones de "reparaciones" y "mantenimiento", que permiten tanto registrar como consultar. En caso de que se seleccione "reparaciones" y luego "registrar", se pide la información de las materias primas e insumos utilizados para reparar una prenda de vestir, así como sus costos (esta información es compartida como la categoría de despacho y el módulo de contabilidad). Si se toma la opción de "consultar", aparece un listado con los materiales e insumos, y con la prenda reparada y el cliente causante del daño de la prenda (esta información es compartida con la categoría de gestión de clientes). En caso que se seleccione la opción "mantenimiento", se despliegan las entradas de "registros" y "consulta". Si se hace clic en la primera se pide la información de la prenda (referencia) que va ir a mantenimiento y los conceptos por lo que va ser atendida, al darle "guardar", coloca la prenda en estado de "mantenimiento", y si se ingresa en la opción "consultar" se puede conocer los datos principales de ello.

\section{- Módulo contabilidad y finanzas (CONTF $\left.F_{1}\right)$.}

Su propósito es tener al día la información contable y financiera, así como las inversiones y costos asumidos.
Estado financiero $\left(C O N T F_{12}\right)$. Si se hace clic en esta categoría, aparece un cuadro de diálogo que contiene las opciones de "estado de resultado", "balance general" y "estado de flujo del patrimonio". Si se ingresa a cada una de ellas, aparece la opción de agregar las "cuentas" y "valores". Cabe resaltar que esta información se alimenta con todas las transacciones realizadas en la empresa como despachos, ventas, pagos, gastos y demás, los cuales se transfieren de los demás módulos de la organización. Así mismo, el modulo guarda la información año por año de los estados financieros realizados, los cuales se pueden consultar por año o por periodo de tiempo deseado.

Costos, gastos e inversiones $\left(C O N T F_{13}\right)$. Dando clic aparecen los niveles de:

- Costos y gastos $\left(\mathrm{CONTF}_{131}\right)$. Al dar clic aparecen dos opciones que contienen por separado las entradas de "consulta" y "registro". Si se toma la opción de "consulta", aparecerá un cuadro en donde se pide el rango de fechas en las que se quieren consultar los gastos o costos. En tanto si se selecciona la opción "registro", se pide la ocurrencia del costo al igual que su valor, luego se hace clic en la opción "guardar" y automáticamente se agrega a la lista de "consulta".

- Inversiones $\left(\mathrm{CONTF}_{132}\right)$. En éste se presentan las opciones de "registrar" y "consultar". Si se toma la opción de "consulta", aparecerá un cuadro en donde se pide el rango de fechas en las que se quieren consultar las inversiones realizadas en campañas y en proyectos (aparece el valor asociado a cada nombre). Pero si se selecciona la opción "registro", se pide el nombre del proyecto o campaña y el valor de la inversión señalada para ello, y, por último, se debe dar "guardar".

Facturas y órdenes de compra (CONTF $\left.F_{14}\right)$. Si damos clic aparecen las siguientes categorías:

- Facturas $\left(C O N T F_{141}\right)$. Al dar clic, aparecen las herramientas "generar", "consultar" y "modificar”. Si se toma la primera opción, se pueden crear las facturas a los clientes (por ejemplo, FA0007435), mediante el diligenciamiento de un cuadro de dialogo que pide como información el nombre del cliente, producto a alquilar, fecha de devolución y abono inicial. En tanto si se toma la opción "consultar", se pueden conocer las facturas realizadas por periodos de tiempo deseados, colocando fecha de inicio y fecha final requerida. Por último, si se selecciona la opción "modificar", se pueden alterar los precios de los productos, en caso de que tengan variabilidad. Cabe resaltar que la generación y modificación de facturas es compartida con el módulo de logística, en la categoría de despachos, con la diferencia de que en este último no se puede realizar modificaciones (solo la sección de administración puede alterar los precios de los ítems). 
- Órdenes de compra $\left(\mathrm{CONTF}_{142}\right)$. Aquí se encuentra la opción de "generar", para ello, luego de ingresar a éste se pide la información necesaria que no se encuentra predestinada, como lo son proveedores, productos a pedir, precio a incurrir y demás. Cabe resaltar que cada orden de compra posee un código, los cuales se pueden restablecer anualmente (por ejemplo, OC0002345). Los códigos de las facturas se pueden restablecer anualmente si se desea, o en caso contrario, mensualmente.

Cuentas $\left(\mathrm{CONTF}_{15}\right)$. Al ingresar, se encuentran las cuentas efectuadas contablemente y sus movimientos por periodo requerido, así como las cuentas bancarias con las debidas transacciones hechas y la opción de modificarlas o eliminarlas en caso de que sea necesario.

Pagos y créditos (CONFT $T_{16}$ ). Si se hace clic en esta categoría, aparecerán los pagos realizados a terceros, así como la posibilidad de registrarlos y consultarlos, también se presentan los pagos de nóminas. Además de ello se puede registrar, consultar los créditos recibidos y el tipo de concepto, así como la entidad crediticia.

\section{- Módulo de Talento Humano $\left(\mathrm{TH}_{1}\right)$.}

Éste tiene como propósito controlar el talento humano de la organización para que estos sean más efectivos y satisfagan las necesidades de la empresa como la de los clientes [18].

Talentos humanos $\left(\mathrm{TH}_{12}\right)$. Si se ingresa a esta categoría, aparecen las opciones de: "Hojas de vidapersonal", en donde se puede consultar las hojas de vida, realizar modificaciones y eliminarlas; "Hoja de vida - aspirante", que permite consultar las hojas de vidas, así como los resultados durante el periodo selección de cada uno de los aspirantes, también es posible realizar modificaciones y eliminarlas; "Contratación", en donde se pueden observar las contrataciones realizadas por trabajador, así como el tipo y su tiempo, y se pueden modificar o eliminar; y finalmente, "Puntualidad", que permite ver la hora de llegada de cada uno de los trabajadores en un periodo deseado.
Programas $\left(\mathrm{TH}_{13}\right)$. Si se ingresa aquí, se encuentran los programas de capacitación e inducción de los talentos humanos, así como los resultados de su evaluación.

Compras $\left(T H_{14}\right)$. Éste permite registrar las compras hechas por concepto de limpieza, dotación y utensilios para los empleados (esta información es compartida con el módulo de contabilidad en la categoría de Factura y órdenes de compras).

Consideraciones: (1) todos los listados (sea de publicidad, proyectos, clientes, proveedores y demás) entregan la opción de borrar dando clic en ellos; (2) la organización posee 3 bodegas; y (3) tanto en la opción de facturas como en órdenes de compra es posible realizar reportes estadísticos.

\section{2) Modelo estructural de la empresa.}

Se determinan las estructuras organizativas de las áreas funcionales de la microempresa Casa Glamel, también los datos y procesos maestros en funcionamiento como resultado de la interacción de los diferentes sistemas y la visión que se tiene de los procesos de negocio junto con las necesidades de optimización.

\section{- Usuarios del nuevo sistema ERP.}

Se contabilizan los usuarios por módulos y se presenta la interacción que existe entre cada uno de ellos (módulos) (Tabla 2).

\section{- Datos maestros y transacciones.}

Se mencionan y contabilizan los datos maestros, los cuales son registros únicos que sirven de referencia, así como sus transacciones (usos o movimientos) por periodo de tiempo señalado (Tabla 3).

\section{- Modelo del sistema}

$E R P$. Se define que el diseño técnico del software será en la totalidad de Casa Glamel, dado a que la organización no posee un sistema de información específico en ninguna de las áreas.

Tabla 2. Usuarios del ERP

\begin{tabular}{|c|c|c|c|c|c|}
\hline \multirow{2}{*}{$\begin{array}{c}\text { Usuarios- } \\
\text { Módulos }\end{array}$} & CRM & $\begin{array}{c}\text { Logística } \\
\text { Interna }\end{array}$ & Contabilidad & $\begin{array}{c}\text { Talento } \\
\text { Humano }\end{array}$ & $\begin{array}{c}\text { Total } \\
\text { usuarios }\end{array}$ \\
\hline Recepción & 6 & 6 & 0 & 0 & 6 \\
\hline Coordinación & 5 & 5 & 0 & 0 & 5 \\
\hline Administración & 3 & 3 & 3 & 3 & 3 \\
\hline
\end{tabular}

* El total de usuarios hace referencia a la cantidad de personas por sección.

Fuente: Modificación de [12]. 
Tabla 3. Datos maestros y transacciones

\begin{tabular}{|c|c|c|c|}
\hline Datos Maestro & Tamaño & Datos Maestro & Tamaño \\
\hline Clientes & 4,000 & Empleados & 12 \\
\hline I.D de clientes & 4,000 & Ubicación de la empresa & 2 \\
\hline Proveedores & 30 & Dirección de proveedores & 30 \\
\hline I.D Proveedores (RUT o NIT) & 30 & Dirección de clientes & 24 \\
\hline Prendas & 15,000 & Productos que ofrecen los proveedores & 50 \\
\hline Referencias de las prendas & 15,000 & Número de trabajadores & 12 \\
\hline Almacenes & 2 & Transacciones/mes & $4^{\prime} 000,000$ \\
\hline Lista de insumos & 40 & Pedidos a proveedores & 20 \\
\hline Lista de materias primas & 50 & Facturas & 180 \\
\hline Artículos de complementos & 20 & Pagos & 5 \\
\hline Referencias de artículos & 15,400 & Confecciones & 2 \\
\hline Ubicación de los almacenes & 2 & Movimiento de stock & 400 \\
\hline Puestos de trabajos & 10 & Alquileres & 200 \\
\hline Ubicación de prendas & 80 & Devoluciones & 200 \\
\hline Entidades de apoyo & 0 & Satisfacción del cliente & 5 \\
\hline$\underline{\text { Cuentas }}$ & (n) & Cumplimiento de empleados & 12 \\
\hline Activos & 300 & Cumplimiento proveedores & 12 \\
\hline Pasivos & 200 & Programas de capacitación & 12 \\
\hline Patrimonios & 100 & Programas de inducción & 12 \\
\hline Centro de costes & 30 & & \\
\hline
\end{tabular}

Fuente: Modificación de [12].

\section{- Arquitectura del sistema informático}

Hardware. Para el correcto funcionamiento del software se hará uso de 4 computadores dentro de la organización que permitirán el manejo del mismo, además, estos deberán estar en conexión con Internet. Por último, para la salida y entrada de información, se cuenta con impresoras y escáneres.

Infraestructura de desarrollo. La infraestructura necesaria para la instalación del prototipo y el software final resultante es: software del sistema, software de redes, software ERP, impresoras, scanner, equipos PC e interfaces con ERP y ordenadores.

\section{Parametrización.}

Se lleva a cabo el desarrollo en términos conceptuales del prototipo para la organización, el cual ayudará a conocer la efectividad del modelo propuesto, $\mathrm{y}$, en dado caso, realizar las mejoras pertinentes. Así mismo, se define la forma tentativa en que será desarrollado el sistema ERP, la cual es concretada en la etapa de instalación.

\section{1) Modelo de empresa.}

Se efectúa la armonización y clasificación de los casos de negocios, datos maestros y estructura organizativa que contribuyeron a la materialización del modelo de empresa plasmándolo en una línea base de procesos. Sin embargo, éste proporciona la información contenida en la actividad de prototipaje, solo que en forma de procesos, por lo que se hará énfasis en esta última.

Prototipaje. Dado que éste es un proceso cíclico, en donde cada ciclo emplea el cumplimiento de un determinado número de casos de negocio, se han efectuado 4 ciclos para esta importante actividad, en donde se presentan la forma en que se debe desarrollar el prototipo y el software finalizado, partiendo desde una línea base (ciclo preliminar) que presenta los primeros elementos a tratar y siguiendo así mismo con los ciclos establecidos, así que, a continuación, se tienen los elementos a instalarse en cada ciclo. Cabe aclarar que ésta es una forma propuesta para obtener el prototipo y el software finalizado, pero que la manera en que se seleccionaran los elementos y ciclos dependía de la capacidad financiera de la empresa para efectuarlo, lo que se define en la 
fase próxima. Además, este método por conveniencia establece en la aplicación que el prototipo haga parte de unos de los ciclos y, así mismo, se vayan añadiendo a éste hasta completar el software.

- Línea de partida. Creación del área de logística interna, datos maestros de clientes, datos maestros de prendas y artículos, datos maestros de proveedores, datos maestros de los trabajadores, inventario disponible, inventario existente, pagos de clientes, pagos a proveedores, reservas, datos maestros de materias primas e insumos, entradas y salidas de materias primas, prendas e insumos, datos maestros de compra, calendario de pedidos a proveedores, fechas de entrega y devoluciones de prendas.

- Ciclo 1. Creación de cuadro de diálogo para la presentación del inventario disponible, creación de la búsqueda rápida del inventario disponible, creación de cuadro de diálogo para la presentación del inventario existente. Determinación de agregar prendas en inventario disponible, consulta y modificación de los productos disponibles, creación de productos en reservas, despliegue de la información de productos de reservas, agregar prendas en la opción "prendas de vestir". Creación de productos alquilados, despliegue de la información de productos alquilados, determinación de consultar productos alquilados. Creación de productos con fallas, determinación del despliegue de la información, opción de agregar productos con fallas. Creación del proceso de seguimiento, buscador de prendas. Determinación de seguimiento de prendas, formación de buscador. Creación de artículos, creación del cuadro del diligenciamiento de la información e ingresos. Creación de alquileres y recibos, creación de reservas de prendas, creación de recibidos. Creación de los sub-niveles de materias primas, insumos y prendas, así como sus buscadores y opciones de agregar. Desenvolvimiento del sub-nivel referencias de materias primas, ingreso de materia prima, creación de registro de consulta y modificaciones. Desenvolvimiento de gestión de compra, consulta y registro, despliegue de la información y agregar. Creación de ventas. Determinación de facturas. Registros de pedidos. Análisis de la información para todos los casos de negocios y procesos. Y finalmente, determinación de proveedores, clientes, artículos, insumos y prendas.

- Ciclo 2. Creación del CRM. Proceso de registro, consulta, evaluación de clientes y clasificación de clientes perteneciente al proceso de registro y consulta de clientes. Creación del nivel proceso de notas. Desarrollo de los niveles de sugerencias (registros y consulta). Creación de la categoría de gestión de proyectos y de sus sub-niveles de registros, consultas, publicidad y encuesta. Desarrollo del proceso de proveedores y de sus sub-niveles de registros y consulta. Determinación de los proveedores, clientes y ventas.
Consideración de que cada módulo, categoría, nivel y sub-nivel requieren de análisis. Determinación de los costos y tiempos de proyectos, publicidad y campañas. Determinación del nombre del proyecto.

- Ciclo 3. Creación del módulo de contabilidad y finanzas. Desarrollo de la categoría de estado financiero y de sus niveles de balance general, estado de resultado y estado de flujo en el patrimonio. Determinación de cuentas, activos fijos, ingresos, gastos y costos. Pagos a trabajadores, clientes y proveedores. Creación del proceso de costos e inversión. Desarrollo de la factura y órdenes de compras. Determinación del número de facturas, clientes y proveedores. Proceso de cuentas. Creación del proceso de pagos y créditos. Determinación de entidades bancarias. Análisis de los procesos. Desarrollo de registros, consultas y modificaciones en los procesos del módulo de contabilidad y finanza. Determinación de la capacidad máxima de endeudamiento, así como de préstamo.

- Ciclo 4. Determinación de los perfiles de usuarios, así como contraseñas y demás. Creación de los reportes estadísticos e informes necesarios. Creación del módulo de talento humano. Desarrollo del nivel de talento humano, determinación de las hojas de vidas de los candidatos y aceptados. Creación de los niveles de compras y programas. Determinación de los materiales e insumos necesarios. Guardar, registrar y modificar los programas y talentos humanos necesarios. Preparación de las pruebas de integración.

Desarrollo de las interfaces. Es necesario que cuando se piense en sistemas informáticos no se focalice únicamente en tecnología sino en gente, por lo cual, se hace importante que el software sea amable con el usuario y que brinde la mayor ayuda e información posible, puesto que es éste quien lo usará [19]. Es por ello que en la Tabla 4, se presentan las interfaces para el software ERP para Casa Glamel.

\section{E. Instalación.}

En esta etapa se lleva a cabo la instalación del prototipado con la finalidad de ver el funcionamiento, desempeño y adaptación de la organización con el sistema de información integral, el cual enmarca los procesos de modelización y parametrización anteriormente definidos. Así mismo, aquí se definen los elementos que serán instalados primeramente y los entregables.

\section{1) Ciclo elegido para la instalación.}

Dado que existe una limitante de capital para la programación e implementación de todo el sistema ERP en conjunto para la organización Casa Glamel, la empresa irá adquiriendo los módulos por medio 
TABLA 4. INTERFACES

\begin{tabular}{|c|c|c|c|}
\hline Interfaz /Tipo & Descripción & Interfaz/Tipo & Descripción \\
\hline $\begin{array}{l}\text { Impresiones y escáneres/ } \\
\text { Permanente }\end{array}$ & $\begin{array}{l}\text { Conexión al sistema ERP para la } \\
\text { opción de información }\end{array}$ & E-mail/ Permanente & Envío de mensajes masivos. \\
\hline $\begin{array}{l}\text { Códigos de barras/ } \\
\text { Permanente }\end{array}$ & $\begin{array}{l}\text { Conexión al ERP principalmente } \\
\text { en el módulo logístico }\end{array}$ & $\begin{array}{c}\text { Resultados esperados y } \\
\text { obtenidos/ Permanente- } \\
\text { Tiempo real }\end{array}$ & $\begin{array}{c}\text { Presentación de los resultados de } \\
\text { proyectos, publicidades y campañas. }\end{array}$ \\
\hline $\begin{array}{l}\text { Acceso vía web/ } \\
\text { Provisional }\end{array}$ & $\begin{array}{l}\text { Acceso al sistema ERP mediante } \\
\text { navegadores como Internet } \\
\text { Explorer } 9.0 \text { o superior, Google } \\
\text { Chrome y Mozilla Firefox. }\end{array}$ & $\begin{array}{l}\text { Importación de datos/ } \\
\text { Provisional. }\end{array}$ & $\begin{array}{c}\text { Que se pueda importar datos que se } \\
\text { requieran. }\end{array}$ \\
\hline \multirow{2}{*}{ Sistema operativo } & \multirow{2}{*}{$\begin{array}{c}\text { Compatibilidad con todo sistema } \\
\text { operativo }\end{array}$} & $\begin{array}{l}\text { Compatibilidad con el paquete } \\
\text { de office }\end{array}$ & $\begin{array}{l}\text { Que sea compatible con el paquete } \\
\text { de office }\end{array}$ \\
\hline & & $\begin{array}{l}\text { Trasmisión de datos/ } \\
\text { Permanente }\end{array}$ & $\begin{array}{l}\text { Trasmisión de datos automático de } \\
\text { un proceso a otro, si así se requiere }\end{array}$ \\
\hline $\begin{array}{l}\text { Roles de usuarios// } \\
\text { Permanente }\end{array}$ & $\begin{array}{l}\text { Que según el usuario existan } \\
\text { restricciones, pero así mismo } \\
\text { entradas a los procesos de los } \\
\text { diferentes módulos }\end{array}$ & $\begin{array}{l}\text { Conexiones sucursales/ } \\
\text { Permanente }\end{array}$ & $\begin{array}{c}\text { Que la información de movimientos } \\
\text { entre las sucursales pueda ser } \\
\text { compartida y manejada por el } \\
\text { usuario pertinente }\end{array}$ \\
\hline $\begin{array}{l}\text { Menú de ayuda/ } \\
\text { Provisional. }\end{array}$ & $\begin{array}{l}\text { Que el ERP brinde ayuda a los } \\
\text { usuarios para la claridad de la } \\
\text { forma de uso del mismo }\end{array}$ & \multirow[t]{2}{*}{$\begin{array}{l}\text { Reporte de movimientos/ } \\
\text { Permanente- Tiempo real }\end{array}$} & \multirow[t]{2}{*}{$\begin{array}{c}\text { Reporte de movimientos de } \\
\text { inventarios, al igual que contables } \\
\text { por periodo de tiempo }\end{array}$} \\
\hline \multirow[b]{2}{*}{$\begin{array}{l}\text { Notificaciones/ } \\
\text { Permanente- Tiempo } \\
\text { real. }\end{array}$} & \multirow{2}{*}{$\begin{array}{l}\text { Presente a los usuarios de los } \\
\text { módulos, notificaciones, como por } \\
\text { ejemplo: reservas a claudicar, } \\
\text { entregas próximas, ventas, } \\
\text { productos alquilados, corbatas } \\
\text { prestadas y demás. }\end{array}$} & & \\
\hline & & $\begin{array}{l}\text { Sistema de almacenamiento/ } \\
\text { Permanente- Tiempo real }\end{array}$ & $\begin{array}{l}\text { Ubicación de la prenda según su } \\
\text { referencia y elección para su alquiler } \\
\text { según su uso por periodo de tiempo. }\end{array}$ \\
\hline \multirow{2}{*}{$\begin{array}{l}\text { Reporte estadístico/ } \\
\text { Permanente- Tiempo } \\
\text { real }\end{array}$} & \multirow{2}{*}{$\begin{array}{c}\text { Que presente repostes estadísticos } \\
\text { en los módulos de CRM, logística } \\
\text { y contabilidad y finanzas. }\end{array}$} & Responsivo & $\begin{array}{c}\text { Que con uso de dispositivos como } \\
\text { celulares inteligentes y tabletas, se } \\
\text { puedan ingresar al sistema }\end{array}$ \\
\hline & & $\begin{array}{c}\text { Reportes e informes } \\
\text { estadísticos/ Permanente- } \\
\text { Tiempo real }\end{array}$ & $\begin{array}{l}\text { Generación de reportes estadísticos } \\
\text { por periodo de tiempo señalado }\end{array}$ \\
\hline
\end{tabular}

Fuente: Modificación de [12].

del cumplimiento de los ciclos de prototipaje, para ello, primero se realiza el ciclo 1 y parte del ciclo 2 , definidos en la fase de parametrización debido a que éste es el que más se encuentra ligado a la actividad de la empresa. Por lo que la instalación del software se da principalmente en el área de coordinación y recepción.

\section{2) Elementos de puesta en marcha.}

Se cuenta con los elementos que hacen posible una buena producción e instalación del software prototipo, los cuales son:

Entorno productivo. El entorno productivo en el que se aplicó el software fue el de los procesos de logística y algunos procesos de CRM, los cuales se muestran en la Tabla 5.

Personal técnico. La organización contrata a un ingeniero de sistemas y éste a sus ayudantes para que realizara la programación del software, tanto prototipo como finalizado.

Estructura del sistema ERP. Se hizo apoyo en la estructura del ERP descrita en la etapa de modeli- zación, teniendo en cuenta la cobertura del ciclo 1 y 2 del prototipaje (Tabla 5) en donde se muestran los procesos de acceso, junto con su codificación, de las secciones que tendrán entradas a ellos.

\section{3) Prueba de integración.}

Debido a que la búsqueda de la integración es un elemento motivador de la mejora continua [20], se llevó a cabo una prueba para valorar la integración del prototipado con respecto a la interfaz, en donde se pudo obtener que se cumpliera con cada una de las herramientas para la integridad del sistema.

\section{Producción.}

La implantación del sistema ERP, muchas veces, es el proyecto de tecnología más grande y transcendente jamás implementado en la organización [9]; sin embargo, como ya se ha aclarado anteriormente, la organización posee limites financieros para la adquisición del software en su totalidad, por lo que irá adquiriendolo ciclo a ciclo. 
Tabla 5. Estructura del sistema ERP

\begin{tabular}{|c|c|c|c|c|c|c|}
\hline \multicolumn{3}{|c|}{ Autorización de acceso } & \multirow{2}{*}{$\begin{array}{c}\text { Prueba } \\
\text { SEC }\end{array}$} & \multicolumn{3}{|c|}{ Secciones } \\
\hline SCNR & GRP & FUNCIONES & & $\mathrm{C}^{*}$ & $\mathrm{~A}^{*}$ & $\mathrm{R}^{*}$ \\
\hline \multicolumn{3}{|c|}{ Proceso de gestión de inventario } & LOG12 & & $\mathrm{x}$ & \\
\hline \multicolumn{3}{|c|}{ Proceso de inventario existente } & LOG121 & $\mathrm{X}$ & $\mathrm{x}$ & \\
\hline \multicolumn{3}{|c|}{ Proceso de productos disponibles } & LOG123 & & $\mathrm{x}$ & \\
\hline \multicolumn{3}{|c|}{ Proceso de productos en reservas } & LOG124 & $\mathrm{x}$ & $\mathrm{x}$ & \\
\hline \multicolumn{3}{|c|}{ Proceso de productos alquilados } & LOG125 & $\mathrm{x}$ & $\mathrm{x}$ & \\
\hline \multicolumn{3}{|c|}{ Proceso de productos con fallas } & LOG126 & $\mathrm{x}$ & $\mathrm{x}$ & \\
\hline \multicolumn{3}{|c|}{ Proceso de seguimiento de prendas } & LOG127 & $\mathrm{x}$ & $\mathrm{x}$ & \\
\hline \multicolumn{3}{|c|}{ ALMACENAMIENTO } & LOG13 & $\mathrm{x}$ & $\mathrm{x}$ & \\
\hline \multicolumn{3}{|c|}{ Proceso de seguimiento de prendas de vestir, materias primas e insumos } & LOG131 & $\mathrm{x}$ & $\mathrm{x}$ & \\
\hline \multicolumn{3}{|c|}{ Proceso de artículos } & LOG132 & $\mathrm{x}$ & $\mathrm{x}$ & \\
\hline \multicolumn{3}{|l|}{ Proceso de despachos } & LOG14 & $\mathrm{x}$ & $\mathrm{x}$ & \\
\hline \multicolumn{3}{|c|}{ Proceso de alquileres y recibidos } & LOG141 & $\mathrm{x}$ & $\mathrm{x}$ & \\
\hline \multicolumn{3}{|c|}{ Proceso de recibidos de nueva materia prima, insumos y prendas } & LOG142 & $\mathrm{x}$ & $\mathrm{x}$ & \\
\hline \multicolumn{3}{|l|}{ Proceso de confecciones } & LOG15 & $\mathrm{x}$ & $\mathrm{x}$ & \\
\hline \multicolumn{3}{|c|}{ Proceso de materias primas, insumos y prendas } & LOG151 & $\mathrm{x}$ & $\mathrm{x}$ & \\
\hline \multicolumn{3}{|c|}{ Proceso de referencia de materia prima } & LOG152 & $\mathrm{x}$ & $\mathrm{x}$ & \\
\hline \multicolumn{3}{|c|}{ Proceso de reparaciones y mantenimientos } & LOG153 & $\mathrm{x}$ & $\mathrm{x}$ & \\
\hline \multicolumn{3}{|c|}{ Proceso de gestión de compra } & LOG16 & $\mathrm{x}$ & $\mathrm{x}$ & \\
\hline \multicolumn{3}{|c|}{ Proceso de consulta de proveedores } & LOG161 & $\mathrm{x}$ & $\mathrm{x}$ & $\mathrm{x}$ \\
\hline \multicolumn{3}{|c|}{ Proceso de registro de proveedores } & LOG162 & $\mathrm{x}$ & $\mathrm{x}$ & $\mathrm{x}$ \\
\hline \multicolumn{3}{|c|}{ Proceso de notas en CRM } & CRMB124 & & $\mathrm{x}$ & $\mathrm{x}$ \\
\hline \multicolumn{3}{|c|}{ Proceso de registro de clientes en CRM } & CRMB121 & & $\mathrm{x}$ & $\mathrm{x}$ \\
\hline \multicolumn{3}{|c|}{ Proceso de consulta de clientes } & CRM122 & & $\mathrm{x}$ & $\mathrm{x}$ \\
\hline
\end{tabular}

${ }^{*} \mathrm{C}$ : Coordinador; A: Administrador; R: Recepción.

Fuente: Autores [14]

\section{1) Software ERP avanzado.}

Con la ayuda del equipo técnico y de desarrollo (investigadores, ingeniero de sistemas y responsables de cada área), se obtuvo el siguiente software del sistema de información ERP implementando en su totalidad la configuración expuesta en la fase de instalación. A continuación, por factores de espacio en el artículo, éste se presenta de forma general.

Para el ingreso al sistema se pide el usuario y su debida contraseña. Cabe resaltar que según el usuario que se utilice se presenta la información de la empresa que le es permitida.

Ingresando con el usuario de administración, quien tiene acceso a toda la información del sistema, obtenemos una primera vista del prototipo (Fig. 6a). En éste se puede ver la ventana de Home, que es la vista de entrada al sistema, y así mismo, a las opciones de inventario, seguimiento de prendas, artículos, proveedores y registros de prendas. Además de ello, se observa el contador de clientes en térmi- nos de sus depósitos diarios y mensuales, así como las facturas obtenidas en meses y días, también se presenta un contador de las reservas del día pendientes y caducadas, al igual se muestran las ventas por mes(es) y día(s), las multas del mes, y además, se tiene la opción de agregar reservas e información sobre las corbatas salientes. Así mismo, en el vértice superior derecho está la opción salir del sistema. Por otra parte, si ingresamos dando clic al "inventario", se obtiene el siguiente despliegue (Fig. 6b).

Entrando a la categoría seguimiento de prenda al dar clic, se puede digitar la referencia del artículo $\mathrm{y}$, así mismo, hacerle seguimiento a la prenda mediante la opción "buscar". También seleccionando las fechas deseadas se puede obtener las ventas por periodo de tiempo en valor monetario. En la pestaña facturas (Fig. 7a), se encuentra la posibilidad de buscarlas digitando su código, así como sus fechas y demás aspectos ya explicados en la etapa de modelización. Además, estas facturas se pueden borrar dado clic en el icono de "borrar", y también se pue- 
den consultar dando clic en el icono correspondiente (lupa), en donde también se encuentra la información de la factura con la opción de "imprimir" (Fig. $7 b)$.

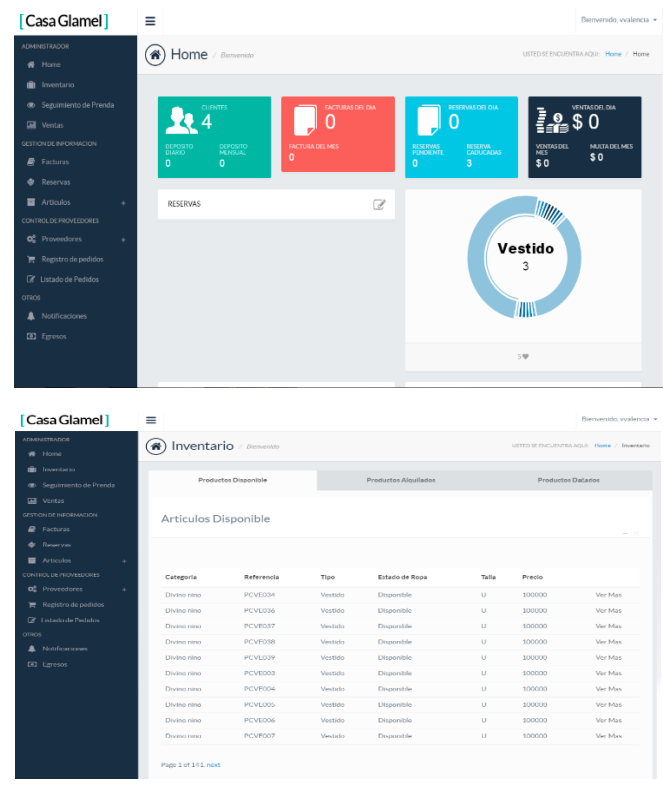

Fig. 6. (a) Vista general del software; (b) Categoría de gestión de inventario Fuente: Autores [14].
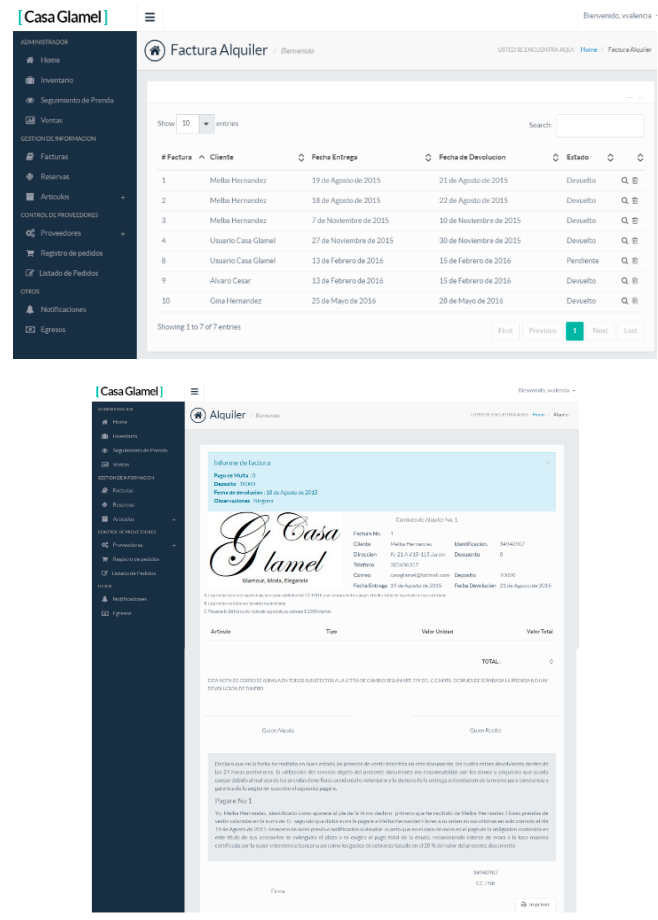

Fig. 7. (a) Factura; (b) Reporte de consulta de factura. Fuente: Autores [14].
Luego, si se hace clic en proveedores de la ventana de home, se abre una lista que contiene crear proveedores y listado de proveedores. Si se ingresa a crear proveedores (Fig. 8a), se puede encontrar un cuadro
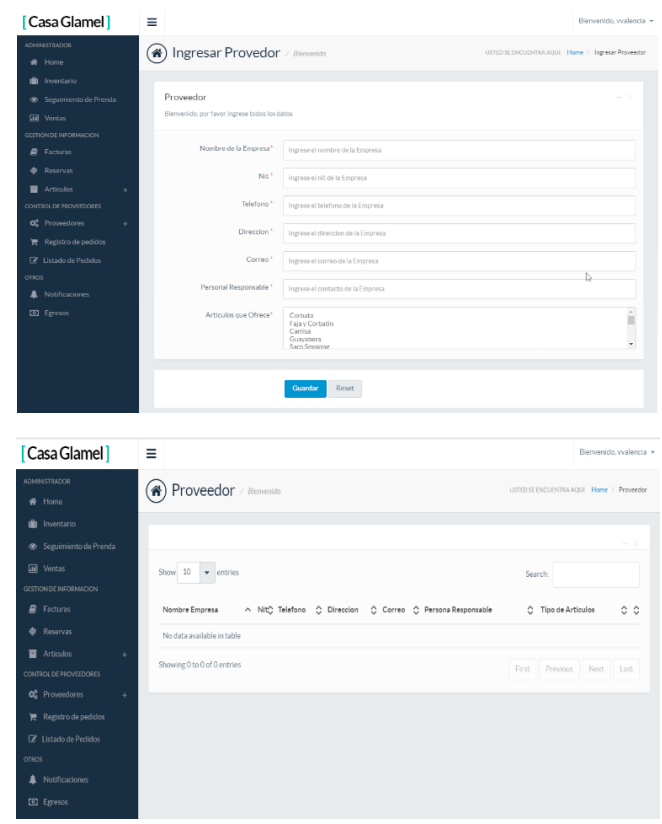

Fig. 8. (a) Proveedores-Crear proveedores; (b) Proveedores-Listado. Fuente: Autores [14].
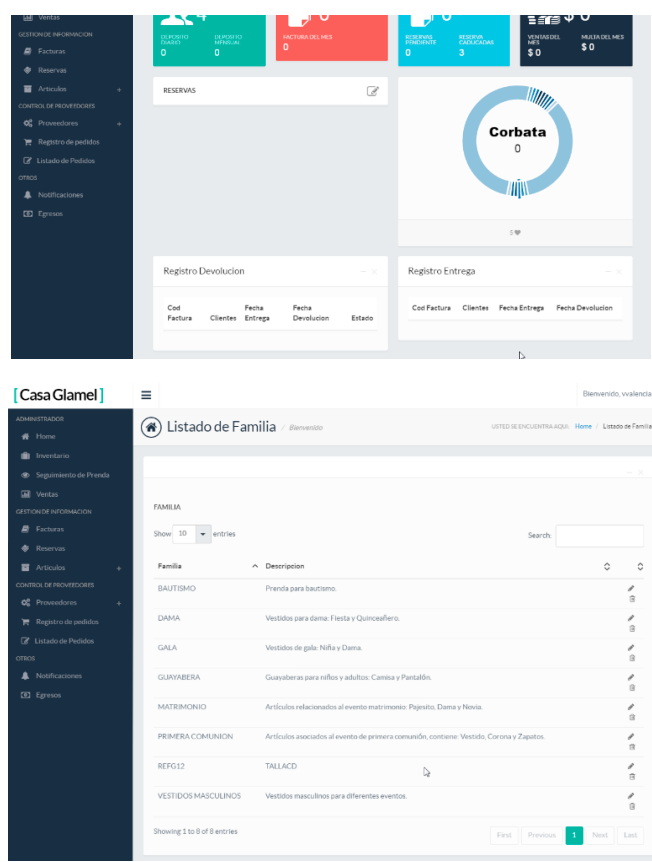

Fig. 9. (a) Registro de devoluciones y entrega; (b) Prendas por familia, categoría y prendas. Fuente: Autores [14]. 
que pide la información necesaria para la creación de proveedores. Es importante resaltar que en la parte inferior se encuentran los artículos que se ofrecen y, así mismo, en la parte superior derecha están las opciones de cerrar la categoría y minimizarla. Por otra parte, si se toma la opción de listado de proveedores (Fig. 8b), se puede encontrar una lista que muestra los proveedores existentes con los datos maestros de los mismos.

En el sub-nivel registro de pedidos de home, se puede hallar un cuadro con la información requerida para registrar los pedidos a los clientes. También se cuenta con el listado de proveedores en donde se puede encontrar el listado de los pedidos realizados a los proveedores de la empresa Casa Glamel junto con los datos maestros necesarios.

De la misma forma, se encuentran los registros de entregas y registros de pedidos (Fig. 9a), los cuales poseen la información de código de factura, clientes, fechas de entrega (registro de devolución), fecha de devolución (registro de entrega) y estado de la devolución. Otra transacción que se puede crear y ver es el listado de artículos por categoría, familia y referencia, dando clic en la opción de artículos y tomando la que se desea (Fig. 9b).

El usuario, en la ruta clientes - crear cliente, tiene la posibilidad de generar y llenar un formato que pide los datos del cliente para registrarlo en la base de datos de Casa Glamel. Al dar clic en guardar, el cliente queda registrado en la base de datos que servirá de soporte para la generación de facturas y estrategias de mercadeo que pueda implementar la empresa; los datos se reflejarán en un listado de clientes que se visualiza al seguir la ruta clientes-listado de clientes.

Cabe señalar que la opción alquiler puede generar factura al cliente, que se obtiene al suministrar los datos: cliente, fecha de entrega, fecha de devolución, depósito y observaciones. Al diligenciar los datos del formulario, el software genera una imagen en donde se ponen en evidencia los datos del cliente y del alquiler que pretende realizarse.

Seguidamente, haciendo clic en la opción “+” se puede agregar los artículos que se alquilarán. Es de destacar que, por políticas de la empresa, se contempla la posibilidad de definir como gratis algunas prendas. Se procede a agregar secuencialmente cada uno de los artículos, y, al finalizar, se hace clic en la opción close, confirmando que se ha registrado la información adicionada; de esta forma, al hacer clic en la opción confirmar, se obtiene la factura totalizada (Fig.9b).

Otra opción presente es la de generar devolución, la cual permite devolver una factura (prenda) determinada. Al ingresar el dato número de factura y hacer clic en la opción buscar, el software refleja la información de la factura junto con las opciones generar devolución e imprimir. Al hacer clic sobre la opción generar devolución, se puede observar desde el listado de facturas que la factura devuelta se encuentra en el estado devolución, lo que significa internamente que los artículos ya se encuentran en el almacén.
Así mismo, existe una opción importante que facilita la creación de reservas: crear reservas; al hacer clic se refleja un formulario que requiere de los datos: cliente, fecha de reserva, fecha límite y abono inicial. $\mathrm{Al}$ hacer clic en la opción siguiente en el cuadro de diálogo, se refleja la información tomada del cliente de la base de datos y requiere que se agreguen los artículos que se van a reservar.

Además, los siguientes pasos son equivalentes a los estipulados en el proceso de generación de factura hasta el momento de su confirmación, en el cual, al hacer clic sobre confirmar, se reflejan los datos de la reserva y muestra la opción imprimir. Cuando se dirige hacia la opción de reservas, el software refleja un calendario que indica las fechas de reserva. Cabe aclarar que se puede visualizar por meses, semanas o días. Así mismo, desde esta ventana se permite realizar modificaciones en cuanto a la fecha de alguna reserva. Por otro lado, cuando se requiera consultar información sobre alguna reserva existe la opción consultar reserva que con tan solo hacer clic y diligenciar el número de factura reflejará lo que se requiere.

Por último, mediante un contacto directo de los investigadores con el área productiva y administrativa de la organización, se pudieron obtener estimaciones del impacto ocasionado después de la aplicación parcial del nuevo sistema. Allí se aprecia una disminución significativa en los tiempos y costos de los procesos de la organización en un promedio del 63,7\%. Además, la integración, confiabilidad y calidad de la información, que son temas muy importantes para la empresa, tuvieron una gran mejoría (Tabla 6).

TABLA 6. ImpaCtos OCASIONADOS POR EL SISTEMA

\begin{tabular}{|c|c|c|c|c|c|c|}
\hline \multicolumn{2}{|c|}{ Variables } & LOG 12 & LOG 13 & LOG 15 & LOG 16 & CRM 12 \\
\hline \multirow[t]{2}{*}{ Tiempo } & antes & 3 dias & $6,10 \mathrm{~min}$ & NA & NA & $5,23 \mathrm{~min}$ \\
\hline & Despues & $1 \mathrm{dia}$ & $2 \mathrm{~min}$ & NA & NA & $2,23 \mathrm{mn}$ \\
\hline \multirow{2}{*}{$\begin{array}{l}\text { Talento } \\
\text { Humano }\end{array}$} & antes & 2 & 1 & 0 & 0 & 1 \\
\hline & Despues & 2 & 1 & 2 & 2 & 1 \\
\hline \multirow[t]{2}{*}{ Costo (\$) } & antes & 147543,40 & 104,168 & NA & NA & 89,312 \\
\hline & Despues & 49181,133 & 34,154 & NA & NA & 38,081 \\
\hline \multirow{2}{*}{$\begin{array}{l}\text { Acceso a la } \\
\text { información }\end{array}$} & antes & Baja & Baja & Regular & NA & Baja \\
\hline & Despues & Alta & Alta & Alta & Alta & Alta \\
\hline \multirow{2}{*}{$\begin{array}{l}\text { Confidencial } \\
\text { idad }\end{array}$} & antes & Baja & Baja & Baja & NA & Baja \\
\hline & Despues & Alta & Alta & Alta & Alta & Alta \\
\hline \multirow[b]{2}{*}{ Integración } & antes & Baja & Baja & Regular & NA & Baja \\
\hline & Despues & Alta & Alta & Alta & Alta & Alta \\
\hline \multicolumn{2}{|c|}{$\begin{array}{c}\% \text { de decremento de } \\
\text { costos }\end{array}$} & $66,7 \%$ & $67,2 \%$ & NA & NA & $57,4 \%$ \\
\hline \multicolumn{2}{|c|}{$\begin{array}{c}\% \text { de decremento de } \\
\text { tiempo }\end{array}$} & $66,7 \%$ & $67,2 \%$ & NA & NA & $57,4 \%$ \\
\hline
\end{tabular}

* Los costos son la penalización en pesos del tiempo empleado en cada categoría compactada, teniendo en cuenta el SMMLV devengado por los trabajadores y el talento humano utilizado. Además, la valoración NA (No Aplica) hace referencia a que la calificación de dicha categoría es cualitativa y no es valorada cuantitativamente, con excepción de las calificaciones en la variable tiempo en los factores LOG 15 y LOG 16 , que no existían dentro de la actividad de la empresa antes de la implementación del ERP, por lo que no pueden ser contrastados.

Fuente: Autores [14] 
Con este diseño se puede atender a los problemas presentados en la organización, teniendo en cuenta que la valoración del impacto totalizado del sistema ERP en la empresa queda fuera del alcance de este estudio, puesto que, como fue expuesto, el sistema no ha sido implementado en su totalidad y se necesita tiempo para la consecución del capital que permita la instalación de los módulos restantes.

\section{Conclusiones}

Durante la ejecución del proyecto se puso en evidencia que es de suma importancia la fase de preparación, pues brinda las herramientas necesarias para prever problemas que se pudiesen presentar a futuro por falta de una planificación previa; además, la modelización y parametrización son puntos de gran relevancia, puesto que en estas fases se centra la columna del ERP, y es en donde se realiza un buen esfuerzo para la construcción debida del sistema de gestión empresarial. A su vez, se alcanzó a demostrar que los sistemas ERP son una herramienta poderosa de importante valor que ayudan a las organizaciones a disminuir la variable costos, obteniendo más control en los diferentes procesos que allí se efectúan y aumentando la utilidad de la empresa.

De igual manera, es necesario destacar que sí es viable llevar a cabo el diseño e implementación de un sistema ERP en MiPyMES, sin embargo, es necesario contemplar la posibilidad de llevar a cabo la ejecución del proyecto de manera progresiva; esto para no generar un impacto de gran magnitud en el aspecto económico, operacional y de recursos humanos de la compañía.

Un punto a tener en cuenta es que para el administrador de la organización es importante llevar a cabo un seguimiento periódico de los cambios positivos en los diferentes procesos y áreas de la empresa en los cuales ha contribuido la implementación del sistema ERP (se recomienda el uso de indicadores) para generar conciencia en el personal de la importancia del mismo; esto debido a que en muchos casos las MiPyMES están compuestas por un recurso humano que necesita de pedagogía en el tema.

Por último, se puede decir que a pesar de que cada sistema ERP es diferente, debido a que cada organización tiene su propia medida de alcance, requerimientos, procesos y recurso humanos; este documento contribuye a futuras investigaciones, sirviendo de apoyo como una guía metodológica práctica en un hipotético proyecto de diseño e implementación de un sistema de recursos empresariales en otra MiPyME.

\section{Financiación}

Artículo derivado del proyecto de investigación titulado: "Diseño de un sistema ERP para el mejoramiento competitivo de la microempresa Casa Glamel", financiado por la Universidad del Magdalena y la organización Casa Glamel. Fecha de inicio: julio de 2015, Fecha de finalización: marzo de 2016.

\section{Referencias}

[1] G. Martine, "O lugar do espaço na equação população/meio ambiente" R. bras. Est. de pop., vol. 24, no. 2, pp. 181-190, dic 2007.

[2] Dinero, “Por qué fracasan las pymes en Colombia?” 2015. [Online]. Available: http://www.dinero.com/economia/articulo/ pymes-colombia/212958. [Accessed: Mar 14, 2017].

[3] C.R. Mejía, "Sistema de Control para las pequeñas y medianas empresas (SICOP)" Rev. Univ. EAFIT. vol. 38, no. 125 , pp. 72 86, mar. 2002.

[4] O.J. Solano, D.G. Pérez y J.J. Bernal, "Influencia de la implementación del sistema de información sobre el rendimiento en pequeñas y medianas empresas; un estudio empírico en $\mathrm{Co}$ lombia," Rev. Investig. Neg. vol 30, no. 52, pp. 31-43, dic. 2014

[5] K.C. Laudon y J. P Laudon, Sistemas de información gerencial. México D.C, México: Pearson Education, Inc, pp. 11-51, 2012.

[6] R.H. Ballou, Logística: administración de la cadena de suministro. México D.C, México: Pearson Education, Inc., pp. 326 330, 2004.

[7] M.I. Lopez "Análisis, diseño y desarrollo de un sistema de información para soportar el proceso de inventario y de prés. tamos de libros de la biblioteca de la Institución Educativa Alejandro Vélez Barrientos del municipio de Envigado," Tesis Pregrado, Dept. Tecno., Sistema. Basic. Tecno. Ing., UNAD., Medellín, Colombia, 2013.

[8] R. Lapiedra., C. Davece y J. Gurial. Introducción a la gestión de sistemas de información en la empresa. 1a ed., pp. 15 jul, 2011. [Online]. Disponible: http://repositori.uji.es/xmlui/bitstream/handle/10234/24161/S53.pdf

[9] A. Garcia- Holgado y F. J. Garcia-Peñalvo, "Estudio sobre la evolución de las soluciones tecnológicas para dar soporte a la gestión de a información," Universidad de Salamanca, Salamanca, CA, Tech. Rep. GRIAL-TR-2015-001, abril, 2015.

[10] M.A. Villanueva, "Planteamiento de un método para implementar un ERP con un modelo de costeo para gestión de em presas de catering en la ciudad de Arequipa," Tesis de pregrado, Dep. Ing. Sist., Universidad Católica de Santa María, Arequipa, Perú, 2017.

[11] Y.A. Uenura y M. Vivaldini, ERP: análise dos módulos de um software aplicável à indústria moveleira. FACESI 5 (2), pp.1-7, jul. 2013. [Online]. Disponible: http://uniesp.edu.br/sites/_biblioteca/revistas/20170808114541.pdf

[12] F.L. Díaz y A.M. Navarro, Sistema de gestión integrado para las empresas (ERP). Madrid, España: Universidad de Alcalá de Henares, pp.12-185, 2014

[13] E. Iberti, P.Pytel y M.F. Pollo, "Propuesta de modelo para la evaluación de la viabilidad de proyectos ERP en el marco del sector público argentino", en XVII Works. Investigadores en Ciencias de la Computación, Salta, Argentina, pp.1-5, 2015.

[14] O.J. Ospino y V.E. Valencia, "Diseño de un sistema ERP para el mejoramiento competitivo de la microempresa Casa Glamel,” Tesis pregrado, Dep. Ing. Indust., Unimagdalena, Santa Marta, Colombia, 2016

[15] R. Naranjo, "El proceso de selección y contratación del perso nal en las medianas empresas de la ciudad de Barranquilla (Colombia)," Rev. Pensam. Gest. No. 32, pp. 83-144, jul. 2012.

[16] V.O. Duke, M. Navarro, G. Díaz, Y. Pérez y M. Vargas-Lombardo, "Exploración en los sistemas CRM/ERP como estrategias en el sector PYMES," Rev. Inic. Cient, vol. 2, no. 2, pp. 86-94, dic. 2016

[17] J.P. Mancera y C.F. Hernández, "Modelo integral 5d`s, diagnóstico empresarial y tecnológico para evaluar la pertinencia y selección de un sistema ERP”. Documento de trabajo, Escanógrafos FCE, no.51, pp.1-34, may. 2013.

[18] M.V. Nagua, "El control interno en las PYMES familiares, una oportunidad para mejorar la competitividad empresarial," Tesis pregrado, Dep. Cont. Aud., Universidad Técnica de Machala, Ecuador, 2016.

[19] L. Cayola, "Recomendación de métodos de usabilidad para proyectos software centrados en el usuario," Tesis pregrado, Dep. Ing. Inf., Universidad Autónoma de Madrid, Madrid, España, 2016.

[20] P.A. Conceição y F González-Ladrón-de-Guevara, "Maximización de los beneficios de los sistemas ERP," Journal of Information Systems and Technology Management, vol. 7, no. 1, pp. 5-32, ene. 2010 . 